\title{
Democratic Socialists on Social Media: Cohesion, Fragmenta- tion, and Normative Strategies
}

\author{
Christopher C. Barnes \\ University of Colorado, Boulder, USA, Christopher.C.Barnes@colorado.edu
}

\begin{abstract}
This essay focuses on members of the Democratic Socialists of America (DSA) political organisation in the US and the ambivalence of using social media as a primary means of communication for socialist information and culture. Relying on in-depth interviews with fifteen active members and leaders in DSA, this essay asks: How does socialist communication on social media encourage both cohesion and fragmentation for activists within the DSA? Locating and analysing key tensions felt by DSA members in response to their use of Facebook and Twitter, this project sheds light on the ways in which socialism is presently communicated to publics and counterpublics and identifies important challenges for the expansion of the socialist movement.
\end{abstract}

Keywords: Democratic Socialists of America, digital socialism, critical internet theory

\section{Introduction}

Many politically active and engaged individuals in the United States currently adopt a socialist political identity in their digital communication and participation. The expansion of digital information about socialism in the US in recent years emerges from important contemporary political campaigns and victories, such as those of Bernie Sanders and Alexandria Ocasio-Cortez, but also from political continuities rooted in progressive social movements since the late 1990s and the recent proliferation of socialist magazines, podcasts, and journalism.

This contribution to triple C's special issue "Communicative Socialism/Digital Socialism" focuses on members of the Democratic Socialists of America (DSA) political organisation in the US and the ambivalence of using social media as a primary means of communication for socialist information and culture. Relying on in-depth interviews with fifteen active members and leaders across the US in the DSA, this essay asks: How does socialist communication on social media encourage both cohesion and fragmentation for activists within the DSA?

Locating and analysing key tensions felt by DSA members in response to their use of Facebook and Twitter, this project sheds light on the ways in which socialism is presently communicated to publics and counterpublics and identifies important challenges for the expansion of the socialist movement.

Building on perspectives from alternative media and Critical Internet Studies, this essay explores challenges DSA members face as they are compelled to use social media platforms to advance their visions of socialism while simultaneously contending with structural conditions often inimical to developing a strong socialist culture. Alternative media theorists recognise the potential for digital communication to expand access to information for activists (Downing 2001), and acknowledge the ways in which the Internet blurs the boundaries between mainstream and alternative media (Atton 2003). Social media platforms in particular offer potential for social movement organisations to develop their narrative capacities, building cohesion through their shared 
struggles and radical political frames (Tufekci 2017; Wolfson and Funke 2014). However, within these commercialised spaces, where user data is commodified and sold to third party advertisers and corporations dictate the structures for participation, significant challenges arise for activists invested in cultivating and spreading a socialist worldview.

Digital communication tools carry the potential to advance grassroots socialism, but this potential is antagonistically entangled in the dominant structures of informational capitalism (Fuchs 2009a). Even among socialists, the commercial affordances of social media encourage individuation and fragmentation as users contend with pressures encompassing the accumulation of likes, retweets, shares, and the production of sensationalized and isolating messages. Socialist cultures developed online can undermine face-to-face organising efforts as status hierarchies and infighting emerge in digital spaces, constituting barriers which discourage participation. Furthermore, the overwhelming flood of information circulating online, often decontextualized and partial, challenges activist organisations as users rely on affective strategies to navigate political communication within structures that favour individual political opinions over listening and collective coordination (Andrejevic 2013; Dean 2009; Fenton 2016). Despite these structural limitations, socialist media consistently circulates through digital spaces.

DSA members consume and produce critical media most often at the level of content rather than form. These media tend to include critiques of capitalism, domination, and oppression, and regularly present marginalised voices while providing information absent from corporate sources (Fuchs 2010). Although the modern socialist movement in the US includes many competing versions of socialism, DSA members working in leftist media outlets such as Jacobin regularly question how to best introduce socialist ideas into mainstream discourse, and this requires at times abandoning prefigurative production practices of anarchist and other radical media to ensure mass circulation and appeal (Fuchs 2010; Sandoval and Fuchs, 2010). Decisions and debates about using platforms such as Facebook and Twitter to advance socialist politics cohere around similar themes as DSA members recognise the significant limitations and risks associated with social media but are compelled to use them in order to disseminate socialist political information. This ambivalence positions activists to develop normative strategies to navigate social media affordances in ways that minimise fragmentation and infighting in favour of building a culture of solidarity online for socialist organisations.

This essay proceeds in four sections. First, I describe the DSA as an organisation, and offer a brief picture of the participants in this project and their media habits. Second, I detail aspects of social media use that promote cohesion and solidarity among DSA members through media criticism, humour, and the distribution of socialist narratives. Third, I explore how social media produces fragmentations among these socialists, focusing on frustrations felt by users who contend with significant barriers to participation in the larger discourse on socialism. Next, I discuss normative strategies developed by socialists to mitigate the problems surrounding social media use and connect this to the growth of socialist media institutions. Finally, I offer suggestions for the DSA, as the organisation develops, to organise around the decommodification of communication.

Overall, this project attempts to contribute initial empirical research that explores the following questions: What are the advantages and limitations of social media use for socialists in the DSA? And, what strategies do DSA members develop in response to the structural constraints of social media platforms? 


\section{The Democratic Socialists of America}

The DSA is the largest socialist organisation in the United States with approximately 56,000 dues-paying members. The organisation is not a political party but an activist organisation that mobilises members and coalitions in both local and national contexts to fight for political gains for the working class through electoral campaigns, direct action, and political education. In 2016, DSA made enormous membership increases initially as a result of the Bernie Sanders presidential campaign, and later in the aftermath of Donald Trump's victory. Bernie Sanders himself is not a member of DSA, but identifies as a "democratic socialist" and aligns with many of the organisation's positions on issues such as universal healthcare, housing justice, and addressing the climate crisis.

During his first presidential campaign, DSA endorsed Sanders and held a coordinated "We Need Bernie" campaign, growing the membership from 6,500 members in the fall of 2014 to 8,500 on election day of 2016 (Schwartz 2017). Although the connection to Sanders supported the growth and development of the organisation, the ascendancy of the political right also fuelled DSA's recent explosion in membership. The day the United States elected Donald Trump as its president, 1,000 new members joined DSA, followed by over 13,000 additional members from November $9^{\text {th }}$ to July $1^{\text {st }}, 2017$ (Schwartz 2017).

Although mainstream media discourse often makes sense of the DSA through the prism of progressive political legislation in the US, such as the Medicare for All campaign or the Green New Deal, the organisation contains a complex array of political ideologies and varies considerably from chapter to chapter across the country. DSA's positions, strategies, and tactics are not necessarily products of broad consensus within the organisation, but instead emerge through intense contestation among a constellation of Marxists, anarchists, social democrats, and others, all with a variety of visions for successful socialist strategy in the twenty-first century. Despite these rich political varieties and differences, there are certainly generalisable patterns within DSA's politics. For the most part, the political culture of the DSA disregards prefigurative theoretical and revolutionary requirements for members and instead attempts to "meet people where they are at", in terms of their everyday working lives to make socialism as accessible and universal as possible.

Many view the recent interest in DSA as a generational phenomenon, citing the fading memory of the Cold War, the financial crisis of 2008, and the material conditions and diminishing future prospects of millennials and generation $Z$ in the US. Along with these explanations, people outside of the organisation also tend to see it as disproportionally white and male, often conflating inaccurate stereotypes of Bernie Sanders supporters ("Bernie Bros") with DSA membership. Although there are certainly aspects of truth to these ideas, they also function to erase the consistent labour in the organisation from marginalised identities and obscure the generational continuities between contemporary socialists and the socialist tradition in the US.

The fifteen voices of DSA members and leaders included in this project reside in many different local contexts and chapters across the country, including New York City, Austin, Chicago, and Denver. Many of these DSA members joined the organisation after the 2016 election, feeling compelled to "do something" in response to Trump's victory. Often disillusioned with the mainstream democratic party establishment, these members sought out a political organisation that offered new possibilities for progressive gains in the US. Some members adopted a socialist political identity before joining the DSA, but others started paying dues to the organisation with a curiosity, experi- 
mentation, and openness about their political identification and only later called themselves socialists after sustained time within their chapters. Certain members felt driven to the DSA by particular issues, such as housing justice, and then expanded their repertoire of socialist positions through conversation, discussion, organising, and political education in their local chapter. Other members developed their socialist politics earlier, through prior activism such as participating in the Occupy Wall Street movement. Most of these participants encountered leftist media in the US prior to joining the DSA, and cited examples such as Democracy Now! and The Nation as contributing to their developing socialist political identity.

In terms of their everyday media habits, the majority of these fifteen activists primarily use Twitter and Facebook to communicate about socialism, to consume socialist information, and to learn about activist events. Although most of these participants consume a wide variety of alternative and mainstream news sources, including, for example, Jacobin, The Intercept, and In These Times along with The New York Times, all of these media are typically filtered through social media. The dependence on social media for socialist information produces significant ambivalence for these DSA members, who recognise many of the inherent restrictions of these platforms but also find them necessary for a variety of practical purposes. The following sections of this essay detail the cohesion and fragmentation produced as DSA members struggle to build socialism using social media, contending always with their structural constraints.

\section{Cohesion}

Digital media and their affordances provide practical ways for activists to meet their communication needs. Alternative media theorists cite the potential for digital communication tools to allow "working people, sexual minorities, trade unions, protest groups", and "people of low status in terms of their relationship to elite groups" a chance to speak for themselves, even if this speaking is done through the use of dominant forms of technology (Atton 2002, 11; Downing 2001; Downing 2003). Modern activists certainly utilise a variety of Internet tools consistently to distribute media and capture audience attention, to collaborate among networks and coalitions, to share strategies and best practices, and to develop political knowledge and awareness (Fenton 2016). Activist communities in particular depend on social media for affective and informational purposes. Facebook and Twitter fulfil basic desires to connect with reference networks, which allows users to feel a sense of belonging (Tufekci 2017). Social media provides opportunities for users to reveal "private preferences to one another and discover common ground", a type of practical communicative activity that serves the explicit political purpose of letting people know they are not alone in their dissent (Tufekci 2017, 48). Related, activists rely on social media to frame and spread their worldview through narratives that reframe hegemonic political understandings (Tufekci 2017; Wolfson and Funke 2013). Of course, these affordances exist in tension with the recognition of the profit motive and commercial nature of social media platforms. Socialist activists in particular recognise the compulsion to use popular commercial communication tools, such as Facebook and Twitter, in attempts to "meet people where they are at", and to present socialist narratives and propaganda.

Although DSA's recent explosion in membership resulted partially from presidential politics, many DSA members joined the organisation after encounters with leftist media 
on social media. Maria Svart ${ }^{1}$, DSA's National Director, explained to me that media sources play a significant role in the organisation's membership growth. She clarified, "Twitter is a huge source of membership [...] When we ask people why they join, a lot of people answer Twitter". Of course, DSA maintains a strong social media presence (@DemSocialists, for example, has over 217,000 followers on Twitter, as of 15 November 2019), but when members talk about joining as a result of Twitter they most likely are referring to the boarder socialist discourse on the platform that includes both official DSA accounts as well as unaffiliated individuals or institutions that share DSA's politics. Maria acknowledged both the benefits and limitations of this reality, describing how the resulting demographics in DSA skew younger but increases in dues-paying members become somewhat self-sustaining as members invite their connections to participate.

This perspective is consistent with DSA members around the country, many of whom experienced the idea of socialism initially on social media. Marco, a member of the Denver chapter, told me that leftist book groups on Facebook helped him realise his socialist identity because he witnessed "all these other people who also identified as socialists and shared these values". Another member, Ava, told me that when she became active in her DSA chapter in Texas, other members from around the country followed her Twitter account and made her feel welcome in the organisation through likes, supportive messages, and retweets.

DSA members appreciated forms of socialist media criticism that occur within social media platforms. Members valued how their fellow DSA members reacted to certain news items on Twitter and Facebook because it provided a "socialist lens" on mainstream accounts of politics. Dylan, a member who lives in New York City, described how horrified he felt after Trump ordered a missile strike on a Syrian airfield in April of 2017 and cable news in the US adopted a tone of reverence and amazement in response $^{2}$. He cited a segment on MSNBC, when Brian Williams described the missile strike as "beautiful", explaining that moments like this show "a seismic splinter between true leftists and corporate Democrats who are okay with the US exercising our military might for really no good reason". At the time, Dylan quickly discovered that his network of connections online, including the leftist media he followed, shared his disgust in this moment.

DSA members also disclosed that they cherished the leftist humour that regularly circulated through their social media networks. Humour binds socialists together often through sardonic criticism of mainstream liberals, corporate Democrats, and liberal journalists. Miguel explained to me that socialist humour online, either from other social media users or leftist media accounts, often points out the "contradictions or obvious inaccuracies or oversights in mainstream accounts", which can help you to "maintain sanity when you're dealing with depressing topics". Other members felt that leftist humour also normalised socialist ideas by translating feelings of anxiety that accompany the adoption of a radical political identity into welcoming entry points. Meagan Day ${ }^{3}$, for example, explained to me how a specific Twitter account, @LarryWebsite, contrib-

${ }^{1}$ Interview participants in this project who are also public figures consented to use of their full names. I indicate each time this occurs throughout the essay. All other participants are identified using pseudonyms.

${ }^{2}$ See Greenwald's (2017) article for a description of the bi-partisan praise in mainstream media of this missile strike.

${ }^{3}$ Meagan Day is a staff writer for Jacobin and an important figure in the DSA and the American socialist movement. 
uted in part to her eventually becoming a member of DSA. Similar to much of the socialist discourse on Twitter, @LarryWebsite was not an official DSA account but it shared many of the organisation's politics and goals through its content. Using memes and other forms of humour, the account advocated strongly for Bernie Sanders over Hillary Clinton in the 2015 Democratic Party primary, and brought levity to the difficulties surrounding Sanders' unfair treatment and eventual loss. She explained to me,

It was just funny and fun, and it felt like a way of uniting socialists. It felt like we had a shared language, and we were funnier than our enemies in the Democratic Party. It made me feel like not only could I be a socialist, but that it could also be fun, and that there were other people that I could laugh with. It really created a sense of community.

Similarly, Marco recounted for me that the first time he met the other comrades in his local chapter at a DSA social event, he already knew all of their jokes and style of humour because he had encountered it on Twitter.

For DSA members, social media can also help to amplify socialist narratives and perspectives. Thomas, a leader in his chapter, described social media as "the biggest microphone we've got for our politics", explaining that without these platforms DSA could not reach large audiences. He cited two examples of viral videos distributed via social media showing DSA members confronting politicians in response to the Trump Administration's "zero tolerance" immigration policy that involves family separations. In one, DSA activists confronted Mitch McConnell, the Republican Speaker of the House outside of a restaurant in Louisville, Kentucky chanting, "Abolish ICE!" and shouting, "Where are the babies, Mitch!?" (Selk 2018; Schwartz 2018). In another, DSA activists in Washington DC confronted Kirstjen Nielsen, former secretary of the Department of Homeland Security, at a local restaurant demanding the end to family separations (Chappell 2018). Both videos allude to DSA's position that advocates for the US to open its borders to all migrants seeking asylum and demands an end to the global capitalist system that allows for the international free movement of capital but not of people (DSA 2018). DSA members viewed public abhorrence over family separations in the US as an opportunity to promote socialist narratives that express moral outrage over family separation, while also offering an analysis that connects these policies to the international rise in nationalism, US imperialism, and global capitalism.

The circulation of socialist perspectives through social media, including media criticism, humour, and the promotion of socialist narratives, certainly serve important functions for the DSA as the organisation continues to grow. Effectively, these practices amount to critical reception of mainstream news and culture, as DSA members "transcend the ideological character of media" and "question the commodified character of the world in which they live" (Fuchs 2009b, 397). The distribution of socialist narratives on social media accomplishes a similar goal, as video footage of demonstrations and protests emphasises the array of socialist political demands. Both critical receptions and socialist narratives stimulate affective bonds between comrades in the DSA, who signal to one another their shared values and common goals. These affective purposes, however, speak more to the plurality of human-centred communication needs, and the pressures exerted on these needs, rather than the particular technological affordances offered by social media. Communicative behaviour is fundamentally part of our species-being, and bound to the "material activity and the material intercourse" of humans (Artz 2006; Macnair 2009; Marx 1932/1978, 154). Social media operate through a dual character of responding to social communication needs felt directly by 
users in this historical moment, while also corresponding to structural pressures and limitations brought about by the colonisation of society by informational capitalism (Williams 1972/2003; Fuchs 2009a, 76). The recursive desire for affective cohesion and solidarity within activist communities online exists as immanently embedded in the contradictions of contemporary communication practices.

\section{Fragmentation}

Although many DSA members cited aspects of social media that they found essential, most of the activists I spoke with expressed intense frustration about these digital tools. Certain members described their activist communication online as exhausting, pointing to constant critiques from users on both the right and left. Thomas, for example, recognised that social media "heightens the degree of emotional labour that goes into being a socialist because you're constantly exposed to your opponents and other people that have very different views than you, and people are pretty vicious on social media". Meagan Day recounted to me how her decision to leave Twitter for a time resulted from the constant criticism she received from other users. She explained,

It was actually detrimental to my ability to do what I felt like I should be doing, which was writing articles that put forth a socialist perspective. I was so troubled by the way that social media colonised my daily life [...] The range of antagonists and protagonists it presented to me. It was very distracting. When you have critics from the left who constantly take pot shots at everything you do, it warps your perspective and you lose the ability to see the real enemy which is the capitalist class.

Any value that social media brings to the DSA comes at significant costs, often exerting strong pressures against activists to contribute in meaningful ways to advancing a socialist worldview.

Other DSA activists recounted feelings of alienation and exclusion in response to particular aspects of socialist communication on social media. Many of the DSA members I talked to reported spending significant time on social media platforms but rarely posting their own messages. Often, they cited feelings of anxiety about posting the "right kind of message" which frequently precluded them from participating in socialist discourse using their own voice. Marco disclosed to me that he is not "much of a poster" on Twitter. When I asked why, he explained, "It gives me some anxiety, socially. I just feel like there's a lot of pressure to say something witty or whatever and that's hard for me to do, so l'd rather just not worry about that". Emma recounted times she felt a desire to participate in discussions online, but worried about posting links to news articles that may not be from a "socialist approved media source". She also remembered a desire to occasionally make a joke but feared that her humour might not be "politically correct". She continued,

I feel like I have to be perfectly on and never say anything wrong, and even if I'm not saying the wrong thing, making sure that's it's worded so that it's clear what the joke is...

As we've seen in this essay, humour plays an important role in forging affective bonds between socialists through political criticism and differentiation often against liberals and members of the Democratic Party in the United States. Humour, however, also 
involves forms of exclusion that, according to members, hold the potential to prevent the expansion of the socialist movement.

Popular forms of socialist humour in the DSA often cohere around leftist social media accounts that use irony and satire to criticise mainstream liberal Democrats and liberal journalists. The typical demographics of people who participate in these forms of humour skew young, male, well-educated, and very well informed on current events and the latest political news. Forms of exclusion emerge as these demographics develop particular codes and inside jokes that enhance affective bonds within the group but alienate outsiders. Paul elaborated on this point, explaining that socialist humour online "creates community that keeps us all clued in to shared jargon and shared inside jokes", but it is also "absolutely repellent to anybody who's not part of it". This description speaks to the emergence of socialist filter bubbles on social media, which reinforce pre-existing views and intensify the exclusionary features and fragmentation of communities online through algorithmic and network structures (Pariser 2011). The risk associated with too many insider-jokes is the foreclosure of universal entry points, undermining the intention of leveraging these platforms to reach mass audiences with socialist perspectives.

Caustic styles of humour among socialists online can promote a type of cohesion when directed against class and political enemies, but the activists I spoke with pointed to the danger of these same tactics used against fellow socialists in the DSA. Micah Uetricht $^{4}$, a member in Chicago, told me how he felt that the negative aspects of socialist humour online can sometimes encourage infighting between socialists in the DSA:

It becomes impossible to just interact, especially with people who are your comrades. It bleeds over into people within the DSA interacting with each other. They don't know how to do it in a way that's not dunking on each other and using humour to try and smack somebody down.

During multiple interviews, DSA members described the risks of alienating older generations, the working class, and women and other minorities with these forms of humour. Maria Svart even recognised the exclusionary dangers that these forms of socialist culture pose. "It's alienating because it's a club", she explained, "and if we're trying to build a mass movement we can't have a club - we just need to speak the language that the people speak".

Members also illustrated socialist discussions on socialist media as radically different than face-to-face communication at DSA meetings. Jenny, a DSA member in New York City, told me that although she found the socialist discourse online quite important, she also described significant incongruences between communication on social media compared to the welcoming atmosphere of physical DSA meetings. Throughout our conversation, Jenny expressed that the characteristics of socialist communication on social media could prevent people from joining DSA because of the tension it can produce. She questioned whether or not people who may be interested in the burgeoning socialist movement may see the discourse on social media and decide not to participate in DSA as a result:

${ }^{4}$ Micah Uetricht is currently Jacobin's Managing Editor and the author of Strike for America: Chicago Teachers Against Austerity. 
[The] level of bad faith and ill will and shittiness online is massive [...] there are times that I look at the discourse and I'm like "Uggghhh, I fucking hate this shit". You know, I'm like, "I don't want to tweet. I don't want to interact with these people. Somebody's just going to bite my fucking head off. No thanks. My life is stressful enough".

Although social media offers socialist opportunities to develop counterpublic identities and present socialist narratives, it also produces forms of exclusion and alienation that work against universal participation in the socialist discourse online.

The ambivalence described above results from the structural constraints of social media. As critical perspectives on the Internet recognise, affordances that allow everyone a voice through digital communication contribute to the endless flood of data online which often supersedes listening, dialogue, and true interaction (Andrejevic 2013; Dean 2009; Fenton 2016). The resulting inundation of opinions and perspectives does not lead to transformative political power nor does it produce significant and sustainable political voices (Fuchs 2009a). Despite the horizontal and chaotic nature of the Internet, platforms hierarchise certain messages over others to populate individually curated user feeds. Particular structural biases, such as the "comment bias" that promotes visibility of quarrels and fights to increase user engagement, shape political communication on social media (Tufekci 2017).

Furthermore, although we must recognise the political potential of humour in alternative media forms (Downing 2001), we also must address the forms of exclusion that arise from what effectively amounts to niche entertainment circulating through commercial media systems and understand the risk of how these forms of communication can displace the hard work of on-the-ground socialist organising (Dean 2009). Additionally, as research on the digital divide shows consistently, Internet users are more likely to be younger, more highly educated and wealthier than non-users, more likely to be men than women, and more likely to live in cities (Fenton 2016). Exclusion along these demographic lines poses a threat for the expansion of the socialist movement to develop universal entry points.

The specific responses from DSA members that detail feelings of anxiety, disgust, and discomfort with presenting their viewpoints on social media emerges in contradiction to liberal notions of digital communication. Socialists on social media contend with unrealised and unfulfilled promises of communicative freedom online. Liberal visions of communication suggest ideas and individuals should have equal access to make public use of their reason and voice their own political opinions. With digital technology, users gain affordances that allow forms of production and consumption that appear as "equal access" but in truth manifest significant forms of hierarchy and dominance.

The multiplicity of perspectives on social media platforms, imbricated by metrics of engagement, popularity, and entertainment values, produces substantial barriers to participation. In effect, though we have gained certain prosumer abilities, we have not freed ourselves from commercial communication that focuses on the "egositic" individual and fragments users from one another and their social communities (Marx 1844/1978). Communicative emancipation must recognise the true interconnective fabric of all social relations and must refuse a conception of people as isolated from one another.

\section{Normative Strategies}

The ambivalence felt by DSA members about social media is well known in the organisation, and there is consistent debate among intellectuals, leaders, and rank-and-file 
members about how socialists should use social media. Strategies for social media use among DSA members seem to parallel other political tactics in the organisation, including work in the electoral realm. DSA differentiates itself from other socialist organisations through a commitment to electoral work and the understanding that elections are the spaces where politics occurs for the majority of ordinary Americans. Thus, in attempts to mainstream socialist ideas, DSA invests significant time and energy into electoral campaigns for candidates that often express explicitly socialist policies and ideals. This is of course not uncontroversial within the organisation, which includes a variety of political perspectives that argue DSA should abandon electoralism entirely. However, these positions do not represent the dominant ideology in DSA, which seeks to shift cultural connotations surrounding "socialism" onto the terrain of everyday life. When I asked about DSA's communication strategy, Maria Svart explained, "The narrative we're promoting is that there's an alternative to capitalism, so our strategies are about normalising democratic socialism, explaining it, puncturing the myths of capitalism and keeping it in the minds of audiences we're trying to reach". This is a struggle that necessarily involves social media.

DSA members and leaders are aware of certain limitations of Facebook and Twitter but feel a political compulsion to use these platforms to "meet people where they are at". The national organisation maintains social media accounts on Twitter and Facebook and chapters around the country run their own accounts with a significant degree of autonomy. Of course, individual DSA members also use social media to communicate about socialism, interacting with DSA posts nationally and locally, but also taking part in the larger discourse on socialism on these platforms. As we have seen, DSA members adopt individual strategies for coping with their own discontents with social media, often avoiding participation despite their desires to connect. Socialists also spend significant time thinking through best practices for using social media for themselves and their organisations, and debate the question of its value for the health of the socialist movement.

Two recent articles published in Jacobin addressed the question of social media for the socialist movement directly. In "Log Off", Benjamin Fong (2018) argued that socialists should advocate for the abolishment of social media platforms, given their tendency to decrease empathy, increase loneliness, and intensify narcissism and cruelty. In response, Meagan Day's (2018) "Unfortunately, We Can't Log Off" acknowledged the significant drawbacks of social media outlined by Fong but argued that socialists must not relinquish these tools to the capitalist class and instead infuse them with a socialist perspective. The strategy she outlined involves socialists adopting particular forms of social media use that retain the promotion and distribution of socialist narratives and politics to large audiences but encourage individual socialists to use institutional accounts and pages instead of personal avatars. Much of the infighting, criticism, turmoil, and antagonism on social media occurs between individual avatars, leaving activists exhausted and distracted. Thus, spreading this obligation between multiple socialists in the same organisation or institution, such as a local DSA chapter, mitigates the damage caused by social media platforms that encourage petty disputes, sensationalised drama, and misinformation. In her words, "Socialists therefore have to toe a fine line: we must maintain a strong and vibrant social media presence, but we can't allow it to atomise us, as it's designed to do" (Day 2018, para. 24).

For Day, this strategy also holds the potential for socialists to develop an ethic and responsibility in the ways they treat their comrades in digital spaces. During our interview she emphasised her above argument, explaining that we should "stop thinking 
about social media as a form of personal expression of individual socialists, and instead as a medium where groups of socialists can come together to further our perspective". She continued,

I think that people should translate their energies to institutional accounts because it naturally involves taking on a sense of responsibility that we ought to have in our [digital communication] [...] The sense of responsibility that people take on to speak on behalf of all socialists.

Countering the pressure for individual socialists to accrue status through platform rewards, or to build up their personal "brand" through Facebook and Twitter, Day's perspective encourages a form of digital solidarity that recognises the marginal position of the socialist movement while attempting to create universal access points for ordinary users. Day's position also speaks to the current context profoundly by gesturing to the contemporary expansion of socialist media institutions.

The recent increase of socialist media institutions in the US is worthy of its own article- and book-length treatment, but the subject holds particular relevance to the growth of the socialist movement in relation to digital communication. Each interview participant in this project mentioned following socialist media outlets regularly and highlighted the ways in which these media contribute in positive ways to their political identification with socialism. Current socialist media include a vast array of institutions including podcasts (e.g. The Dig and Chapo Trap House), political magazines (e.g. Current Affairs, In These Times, and Jacobin), and even video and television (e.g. Means TV and Novara Media).

Many of these outlets adopt a subscription-based funding model, releasing them from problems endemic to liberal public media that tend to tailor their content to their donor class. These media also utilise social media to promote their content, interact with audiences, and to solicit funding. The advantages of a broad variety of leftist media counter many of the problems associated with unorganised socialist discourse circulating on social media platforms. These outlets build audiences, treat political issues typically in a much longer form than Facebook or Twitter posts, and offer avenues to transcend the exclusions often present in fragmented socialist discourse on social media.

An additional benefit to emerging socialist media institutions and organisations are their focus on international relations and the socialist struggle around the world. At the national level, DSA has an active International Committee (2019) that seeks to "connect in solidarity with like-minded activists, workers, movements and parties worldwide" (para. 1). At the 2019 DSA National Convention, the organisation voted to strengthen the International Committee and its efforts connecting to socialists around the world. In addition, the organisation passed resolutions committing to solidarity with Palestine and Cuba, and adopted official anti-imperialist positions that advocate for self-determination, full sovereignty, and decolonisation for countries occupied or exploited by the US. Despite this, the DSA members I spoke with do not seem to interact with socialists in other countries using social media on a regular basis, which constitutes another form of exclusion and fragmentation. However, as audiences of leftist media, these members have consistent opportunities to learn about the international socialist struggle. Jacobin, for example, offers significant and essential international coverage. Micah Uetricht, Jacobin's Managing Editor, emphasised to me that they "insist on going beyond the hegemonic role that the US plays in global politics." DSA as a national organisation and socialist media institutions are positioned well to develop 
interest about the international socialist struggle for individual DSA members, who often cannot learn about these topics through mainstream commercial media in the US, and who may be restricted by the ways socialist discourse on social media retains a national focus.

Alternative media theorists contend that "alternative media" differentiates itself from "mainstream" media through deprofessionalisation, decapitalisation, and deinstitutionalisation (Atton 2002; Hamilton 2001). What we see, however, with emerging socialist media institutions in the US is a commitment to professionalisation, institutionalisation, and the utilisation of commercial techniques to capture the attention of large audiences. For the burgeoning socialist movement in the US, these commitments from socialist media institutions may offer an avenue to overcome marginality, where reaching a broad audience is necessary for the large-scale social transformation desired by socialists (Fuchs 2010; Sandoval and Fuchs 2010). Furthermore, institutionalisation, professionalisation, and the ability to mobilise financial resources afford opportunities to expand the scope of content to include significant projects, such as international coverage focusing on socialist issues and politics around the world. Unlike the unorganised socialist discourse circulating through Facebook and Twitter, socialist media institutions and socialist social movement organisations also offer opportunities for activists to distance themselves from the negative effects of individuals shouldering the promotion and distribution of socialist narratives and information. Normative strategies that suggest socialists should participate in social media through institutional and organisational accounts and pages pushes against the ideological character of social networking that encourages "capitalist individualisation, accumulation, and legitimisation", while gesturing to an alternative where platforms would "allow group profiles, joint profile creation, group blogging" explicitly oriented to social justice and collective goals (Fuchs 2009a, 84). This idea, however, comprises only an incipient socialist strategy focused on social media that must be developed to specifically include the labour relation involved in capitalist social media.

\section{Conclusions}

The emergence of social media represents a development in informational capitalism where disposable time is colonised by productive forces, where attention is monetised, and where user data is sold to third party advertisers (Fuchs 2015). Critical Internet theorists demonstrate how users labour for social media platforms through their online activity and digital communication. These perspectives build on Dallas Smythe's (1981) foundational research which theorised how audiences become commodities under commercial mass media systems because, as "audience power is produced, sold, purchased and consumed," it "commands a price and is a commodity" $(1981,25)$. In effect, this is an extension of the notion that media consumption is the prolongation of work, where audience members "work" for advertisers by learning how to buy goods and spend money through the exposure to advertising (Smythe 1981). Audience members labour for advertisers while reproducing their own labour power through leisure time, which is consistently filled with mental and physical work masquerading as "free time" (Smythe 1981).

Christian Fuchs $(2012,146)$ demonstrates how social media users, as they upload photos, write posts and comments, and send messages, function as double objects of commodification: "They are first commodified by corporate platform operators who, sell them to advertising clients, and this results, second, in an intensified exposure to commodity logic. They are permanently exposed to commodity propaganda presented by 
advertisements while they are online". This is, of course, also true for socialists who use social media platforms.

Throughout the interviews I conducted for this project, I did not encounter perspectives from DSA members and leaders that defined social media use as labour. Many members articulated intense ambivalence, and at times incendiary criticisms, of social media platforms and their profit motives. For example, Miguel, a DSA member from the Denver chapter, explained to me how all media dependent on advertising revenue, from television to social media, catered to "an addiction" that people have for sensational and superficial information. He described these media as "sweets, candy, or like crack, or whatever to get people to watch [...] that's clear also in the types of things that get like the most clicks on Facebook or Twitter too - it's like bubble gum, absolute garbage". Similarly, Maria Svart recognised risks associated with DSA members using social media focusing on its profit motive. Citing Facebook as an example, she described the platform as "very authoritarian, privately held, and totally driven by profit [...] at any moment [they] could decide to turn their algorithms against us [...] it's a private sphere and that's incredibly dangerous".

DSA members recognise how commercial media operates, and they often can articulate in sophisticated terms how capitalist media systems damage democratic ambitions. However, the DSA members and leaders I spoke to did not explicitly discuss the labour relation embedded antagonistically between social media platforms and their users. My questions to interview participants focused on the advantages and limitations of social media for the socialist movement, and, as an open-ended in-depth discussion on socialism and communication, I did not explicitly prime respondents with particular topics such as digital labour. Future research should carefully consider avenues to explore how socialists think about digital labour in relation to their greater political ambitions. Furthermore, the lack of discussion around digital labour from participants in this project demonstrates important opportunities for critical media researchers to support organisations like the DSA by exploring and developing socialist strategies for using social media.

A version of "meeting people where they are at" could involve developing issue campaigns centring on social media and mobilising the intense antipathy towards Facebook and Twitter to fight for democratic controls that preserve the potentials to build cohesion and militate against the structures that promote fragmentation. It certainly seems feasible to conduct activist campaigns against social media online, such as $A$ Billion People's call for a digital strike and a series of disruptions against Google, Amazon, and Facebook in September of 2018 (A Billion People 2018). However, organising around these issues could also occur in physical DSA meetings through in-person discussions on the political economy of social media and socialist strategies for digital communication.

In The Idea of Socialism, Axel Honneth (2017) argues that the socialist movement must advocate for the removal of all barriers to communicative freedom to enhance the potential for socialism to articulate itself to social freedom through experimentation and documentation of past attempts at economic collectivisation. Additionally, Honneth (2017) advocates that socialists must finally abandon the proletariat as the revolutionary figure in future iterations of the movement.

The perspectives presented in this project, however, demonstrate the need to retain and expand contemporary understandings of the proletariat. Socialists today must certainly fight for the removal of barriers to free communication in digital realms, but this can only occur through clarifying the labour relationships entrenched in digital communication and organising users to fight against the authoritarian restrictions that remove 
users from participation in shaping the structures that regulate our social lives (Andrejevic 2009). Ordinary users possess the power to bring "corporate social media to a standstill" by withholding their labour through a digital strike or another form of collective disruption (Fuchs 2015, 39).

In general, organised media activism within the DSA could take a number of forms involving strategies such as labour organising, electoral campaigns, and direct action. Currently, DSA does not have a national working group dedicated to media activism, but this does not necessarily mean these goals are not a priority for individual members and chapters around the country. The New York City chapter, for example, includes a "Tech Action" working group that advocates for organising workers in the technology and media industries, and offers a variety of positions and critiques ranging from implementing public control over corporate and government data systems, to exploring the political possibilities of a public Internet infrastructure (Tech Action Working Group 2019). The working group recently collaborated with Julia Salazar, a DSA-endorsed state Senate candidate in New York, to develop a political platform for technology that included, among other positions, making high-speed affordable Internet accessible to all New Yorkers; advocating for "gig" and contract workers to organise and gain collective bargaining rights; providing recourses for platform co-ops, owned and operated by workers; and demanding that technology companies pay their fair share of taxes (Malmgren 2018; Salazar for State Senate 2019). These examples offer important models for socialist media activism on a national level.

Many of the demands socialists could make in respect to digital capitalism involve supporting and imagining policies that transfer resources and power away from social media giants to ordinary users and alternative platforms. Confronting the oligopolistic structures of social media companies requires activists to capture state power and leverage it to tax these firms and channel those resources to non-commercial media institutions and platforms, which would mark an important first step in strengthening the public sphere (Fuchs 2014). At a time when burgeoning socialists media institutions and content begin to attract large audiences through their unique political perspectives and imaginative critical analysis, the possibility of regulations that limit the power of digital oligopolies in favour of non-commercial alternatives seems both timely and necessary.

Demanding greater democratic controls over social media platforms for individual users and social movement organisations could mitigate the challenges experienced by activists as they disseminate their politics and interact in digital realms. Many DSA members work tirelessly online to promote their narratives and events in the face of intense criticism and structural conditions that divide socialist communities. These users, and all users, should have a voice in shaping the rules for engagement on social media. As the socialist movement grows, and as the DSA continues to advocate for the decommodification of housing and healthcare as human rights, the movement should demand the decommodification of communication as a human right.

\section{References}

A Billion People. 2018. Occupy Silicon Valley. http://abillionpeople.org/occupy-silicon-valley/ Andrejevic, Mark. 2013. Infoglut: How the Digital Era Is Changing the Way We Think about Information. NY, New York: Routledge.

Andrejevic, Mark. 2009. Critical Media Studies 2.0: An Interactive Upgrade. Interactions:

Studies in Communication and Culture 1 (1): 35-51.

Atton, Chris. 2002. Alternative Media. Thousand Oaks, CA: Sage. 
Artz, Lee. 2006. On the Material and the Dialectic: Toward a Class Analysis of Communication. In Marxism and Communication Studies: The Point is to Change It, edited by Lee Artz, Steve Macek, and Dana L. Cloud, 5-51. New York, NY: Peter Lang.

Chappell, Bill. 2018. 'Shame!': Protesters Shout At DHS Head Kirstjen Nielsen, Eating At Mexican Restaurant. NPR, 20 June 2018, https://www.npr.org/2018/06/20/621875523/shame-protesters-shout-at-dhs-head-kirstjennielsen-eating-at-mexican-restaurant

Day, Meagan. 2018. Unfortunately, We Can't Log Off. Jacobin, https://jacobinmag.com/2018/12/log-off-social-media-twitter-organizing-facebook

Dean, Jodi. 2009. Democracy and Other Neoliberal Fantasies: Communicative Capitalism and Left Politics. Durham, NC: Duke University Press.

Downing, John D. H. with Tamara Villarreal Ford, Genéve Gil, and Laura Stein. 2001. Radical Media: Rebellious Communication and Social Movements. Thousand Oaks, CA: Sage.

Downing, John D. H. 2003. Audiences and Readers of Alternative Media: The Absent Lure of the Virtually Unknown. Media, Culture \& Society 25 (5): 625-645.

DSA. 2018. Statement on Central American Caravan/DSA se solidariza con la actual caravana centroamericana en un éxodo a los Estados Unidos. https://www.dsausa.org/statements/statement-on-central-american-caravan/

Fenton, Natalie. 2016. Digital, Political, Radical. Malden, MA: Polity Press.

Fong, Benjamin. 2018. Log Off. Jacobin, https://www.jacobinmag.com/2018/11/log-off-facebook-twitter-social-media-addiction

Fuchs, Christian. 2015. The Digital Labour Theory of Value and Karl Marx in the Age of Facebook, YouTube, Twitter, and Weibo. In Reconsidering Value and Labour in the Digital Age, edited by Eran Fisher and Christian Fuchs, 26-41. New York, NY: Palgrave Macmillan.

Fuchs, Christian. 2014. Social Media and the Public Sphere. tripleC: Communication, Capitalism \& Critique 12 (1): 57-101.

Fuchs, Christian. 2012. The Political Economy of Privacy on Facebook. Television \& New Media 13 (2): 139-159.

Fuchs, Christian. 2010. Alternative Media as Critical Media. European Journal of Social Theory $13(2): 173-192$.

Fuchs, Christian. 2009a. Information and Communication Technologies and Society: A Contribution to the Critique of the Political Economy of the Internet. European Journal of Communication 24 (1): 69-87.

Fuchs, Christian. 2009b. Some Theoretical Foundation of Critical Media Studies: Reflections on Karl Marx and the Media. International Journal of Communication 3: 369-402.

Hamilton, James. 2001. Theory Through History: Exploring Scholarly Conceptions of U.S. Alternative Media. The Communication Review 4 (3): 305-326.

Honneth, Axel. 2017. The Idea of Socialism, translated by Joseph Ganahl. Malden, MA: Polity.

Macnair, Mike. 2009. Marxism and Freedom of Communication. Critique 37 (4): 565-577.

Malmgren, Evan. 2018. Democratic Socialist of America-Back Candidate Julia Salazar Challenges Silicon Valley. Salon, August 13. https://www.salon.com/2018/08/13/exclusivedemocratic-socialists-of-america-backed-candidate-julia-salazar-challenges-silicon-valley/

Marx, Karl. 1932/1978. The German Ideology: Part I. In The Marx-Engels Reader, edited by R. C. Tucker, $2^{\text {nd }}$ Edition, 146-200. New York, NY: W. W. Norton and Company.

Marx, Karl. 1884/1978. On the Jewish Question. In The Marx-Engels Reader, edited by Robert. C. Tucker, 26-53. New York, NY: W. W. Norton and Company. Second edition.

Pariser, Eli. 2011. The Filter Bubble: What The Internet is Hiding from You. New York, NY: The Penguin Press.

Sandoval, Marisol and Christian Fuchs. 2010. Towards a Critical Theory of Alternative Media. Telematics and Informatics 27 (2): 141-150. 
Smythe, Dallas. 1981. Dependency Road: Communications, Capitalism, Consciousness, and Canada. Norwood, NJ: Ablex.

Selk, Avi. 2018. 'Where are the Babies, Mitch?': McConnell Pursued from Restaurant by Angry Crowd. Washington Post, 8 July 2018, https://www.washingtonpost.com/news/postpolitics/wp/2018/07/08/where-are-the-babies-mitch-mcconnell-pursued-from-restaurantby-angry-crowd/

Salazar for State Senate. 2019. Tech Platform. https://salazarforsenate.com/issues/tech

Schwartz, Drew. 2018. Protesters Chased Mitch McConnell from a Restaurant Chanting 'Turtle Head'. Vice. https://www.vice.com/en us/article/ne5wvd/mitch-mcconnell-turtle-headchant-protesters-immigration-vgtrn

Schwartz, Joseph M. 2017. A History of Democratic Socialists of America. Democratic Socialist of America, http://www.dsausa.org

Tech Action Working Group. 2019. Materials. https://techaction.nyc/materials/

Tufekci, Zeynep. 2017. Twitter and Tear Gas: The Power and Fragility of Networked Protest. New Haven, CN: Yale University Press.

Williams, R. 1972/2003. The Technology and the Society. In The New Media Reader, edited by Noah Wardrip-Fruin and Nick Montfort, 289-300. Cambridge MA: MIT Press.

Wolfson, Todd and Peter N. Funke. 2014. Communication, Class and Concentric Media Practices: Developing a Contemporary Rubric. New Media \& Society 16 (3): 363-380.

\begin{abstract}
About the Author
Christopher C. Barnes

Christopher C. Barnes is a PhD candidate in Media Studies at the University of Colorado, Boulder. His dissertation explores the communicative practices, structures, and texts central to the resurgence in activist efforts to bring political legitimacy to democratic socialism in the current historical moment in the United States, focusing on the Democratic Socialists of America.
\end{abstract}

